\title{
Efficacy and Tolerability of Topical Polyphenon E in Multiple "Seborrheic Keratosis-Like" Lesions of the Groin in an Immunocompetent 26-Year-Old Man
}

\author{
Luigi Pizzinia $^{a}$ Graziano De Lucab $^{\mathrm{b}} \quad$ Massimo Milani $^{c}$

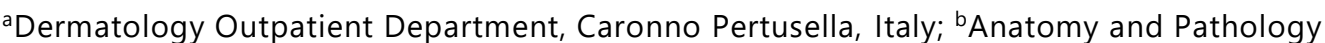 \\ Service "Azienda Socio Sanitaria Territoriale (ASST) della Valtellina e dell'Alto Lario", \\ Caronno Pertusella, Italy; 'Medical Department Cantabria Labs Difa Cooper, Caronno \\ Pertusella, Italy
}

\section{Keywords}

Green tea extract · Genital warts · Bowenoid papulosis · Seborrheic keratosis · Case report

\begin{abstract}
Polyphenon E 10\%, a green tea extract containing epigallocatechin gallate (EGCG) as the main active compound, is a topical formulation indicated for the treatment of genital warts. Polyphenon $\mathrm{E}$ has also shown to be very effective in the treatment of periungual and plane warts. Here, we report a dramatic clinical effect of topical treatment with polyphenon $E$ in a subject with multiple "seborrheic keratosis-like" lesions of the genital area. An immunocompetent 26year-old Caucasian man came to our attention in October 2018. The subject, a regular blood donor, presented several (more than 100) light brown dome-shaped papular lesions in the groin area and in the penile shaft. A clinical diagnosis of Bowenoid papulosis-like multiple condylomata of the groin was made. A 2-month imiquimod treatment did not induce any relevant improvement in terms of volume and number of lesions. A treatment with Polyphenon E, a topical green tea extract with $10 \%$ of EGCG (Veregen ${ }^{\circledR}$ ), was therefore started. After 2 months of Polyphenon E treatment, a dramatic reduction of the majority of the lesions was observed. After 3 months of treatment, all the lesions disappeared with only hyperchromic residues. Histological and immunohistological findings supported seborrheic keratosis as the
\end{abstract}


conclusive diagnosis. This case report suggests that topical green tea extract could be very effective in the treatment of "seborrheic keratosis-like" lesions of the inguinal area.

(C) 2019 The Author(s)

Published by S. Karger AG, Basel

\section{Introduction}

Polyphenon E 10\%, a green tea extract containing epigallocatechin gallate (EGCG) as the main active compound, is a topical formulation indicated for the treatment of genital warts [1]. Polyphenon E, applied three times a day and up to 16 weeks, induced a complete clearance rate in more than $50 \%$ of patients with condylomata [2]. Treatment of genital warts with Polyphenon E shows a very low recurrence rate at 3 months after the conclusion of the therapy $(<6 \%)$. Polyphenon E is a quantified extract of green tea leaves (Camellia sinensis), where the main active substance is epigallocatechin gallate (EGCG), a polyphenol substance which represents the major component of the catechins fraction [3]. EGCG has potent antioxidant, antiinflammatory, and pro-apoptotic actions, which could explain its anti-viral properties [4]. Recent data have shown that EGCG is able to modulate the cellular genes involved in Toll-like receptor (TLR) production and in the apoptosis mechanisms [5]. The product has shown a general good safety profile. Local skin reactions like erythema and edema, in general mild to moderate, were reported in most treated subjects [6]. Polyphenon E has shown to be very effective in the treatment of periungual [7] and plane warts [8]. Seborrheic keratosis (SK) is a common hyperproliferative skin disease affecting mainly the sun-exposed area even if it is also common on the trunk and back [9]. Despite its frequency, the pathogenetic mechanism is still not well understood. SK are also detected in the genital area, but there is a debate regarding the fact that these kinds of lesions should be considered a variant of genital warts, especially if HPV is detected in the affected area [10]. Here, we report a dramatic clinical effect of topical treatment with polyphenon $\mathrm{E}$ in a subject with multiple "seborrheic keratosis-like" lesions of the inguinal area.

\section{Case Description}

An immunocompetent 26-year-old Caucasian man came to our attention in October 2018. The subject, a regular blood donor, presented several (more than 100) light brown domeshaped papular lesions in the groin area and in the penile shaft (Fig. 1). The glans was not affected. The anal region was free of clinical lesions. There were no palpable lymph nodes in the inguinal area. HIV, VDRL, and HCV serum markers were all negative. He denied at-risk sexual intercourses. The lesions get worse after shaving of the affected area. A clinical diagnosis of Bowenoid papulosis-like multiple condylomata of the groin was made. As differential diagnosis, eruptive multiple nevi, SK, and dermatosis papulosa nigra were excluded according with anamnestic, clinical, and dermoscopy patterns. An imiquimod $5 \%$ therapeutic cycle (one application 3 times per week) was started. After 2 months, a very modest reduction of lesions was observed. Few non-inflamed lesions were treated with cryotherapy. After 3 months of imiquimod treatment, no improvement of type, volume, and number of lesions was observed. A biopsy of some lesions was performed. At the meantime, as an "ex-adiuvantibus" approach, a complete 3-month treatment with Polyphenon E, a topical green tea extract with $10 \%$ of EGCG (Veregen ${ }^{\circledR}$ ), was started. After 2 months of Polyphenon E treatment, a dramatic reduction of the majority of the lesions was observed. After 3 months of treatment, all lesions 
disappeared with only hyperchromic residues (Fig. 2). The biopsy (taken before the start of sinecatechins therapy) report stated that the examined lesions showed hyperkeratosis with epidermal pigmented hyperplasia. The skin specimens were negative for $\mathrm{p} 16$ expression with a moderate expression of Ki67 only at the basal level of the epidermis (Fig. 3a-d). SK was the conclusive diagnosis. Treatment was very well tolerated and local tolerability was judged to be very good by the patient. This is the first case report suggesting that Polyphenon E could be effective in the treatment of "seborrheic keratosis-like" lesions of the inguinal area.

\section{Discussion}

Topical green tea extract containing EGCG (Polyphenon E) is considered an effective, well tolerated, self-applicable topical treatment of genital warts in immunocompetent subjects [11]. Several case reports have shown that EGCG is also very effective in the treatment of difficult-to-treat plantar and plane warts [12]. EGCG has an antiviral action trough pathway triggering cell growth arrest and increasing pro-apoptotic molecules like p53 and p16 [13]. EGCG can interfere with cellular activity of E6 and E7, two HPV virus proteins [14]. E6 and E7 are involved in the process of apoptosis inhibition and in the immune evasion mechanisms [15]. Therefore, Polyphenon E could express anti-HPV actions through multiple mechanisms. So far, no case reports on the efficacy of topical Polyphenon E in SK have been reported. SK are common benign skin lesions, affecting mainly the hair-bearing skin area, but they are also common in the trunk area [16]. SK are common among older individuals [17]. SK lesions in some cases present a verrucous appearance but detection of human papillomavirus has been reported infrequently, except in lesions in the genital area [18]. SK located in the genital skin area are relatively uncommon. Genital SK lesions appear in a younger age group than SK from other more common body areas. In 1991, Leonardi et al. [19] demonstrated that SK lesions from the genital region contain human papillomavirus DNA. Therefore, some authors suggest that these kinds of lesions represent condyloma acuminatum [20]. In the differential diagnosis work-up of this case report, we have also considered dermatosis papulosa nigra (DPN) [21]. This skin condition characterized by the presence of many small, benign skin lesions on the face, is generally presenting on dark-skinned individuals [22]. DPN is extremely common, affecting up to $30 \%$ of black people in the US [23]. From a histological point of view, DPN resembles seborrheic keratoses. However, in consideration of demographic data and the body area affected, this diagnosis was excluded. Bowenoid papulosis (BP) should be also considered in the differential diagnosis. BP typically occurs in young sexually active persons [24]. BP manifest as red-brown papules or confluent plaques on external genitalia on the perineum or perianally. BP tends to be benign with spontaneous regression occurring within several months [25]. BP occurs on the genitalia of both sexes in sexually active people [26]. This skin disease seems to be induced by human papillomavirus [27]. Histologically, they are composed of scattered atypical cells or full-thickness epidermal atypia that some view as analogous to squamous cell carcinoma in situ [28]. This epidermal atypia is sometimes known as Bowenoid dysplasia. The histological examination of skin lesions of the present case report supported the diagnosis of SK [29]. Various degrees of hyperkeratosis, acanthosis, and papillomatosis are typical histologic findings of SK [30], and all of these were observed in the histological specimen of this case. In addition, the expression of Ki67 was modest and the expression of p16 absent. These histological and immunohistochemical finding further support the diagnosis of SK. Wu et al. [31] have shown that in BP, there is an increased expression of p16 and Ki-67; interestingly, in the same article, it has been demonstrated that some SK lesions showing 
Bowenoid transformation have higher Ki-67 and p16 expression in comparison with SK lesions without Bowenoid transformation. Expression of Ki-67 in condylomata is observed in more than $88 \%$ of histological specimen, and it is observed also in the spinous layer, a pattern not found in normal skin [32]. In the present case report, however, we did not perform any evaluation of the presence of HPV DNA and consequently we are not able to exclude the viral origin of the lesions. Therefore, the strong clinical response we observed could be simply due to the fact that these lesions were actually SK-like condylomata. However, in evaluating this case report, we must consider additional facts. The clinical response to imiquimod was practically absent, questioning the predominant viral nature of the lesions. In addition, the absence of p16 expression and the modest expression of Ki-67 do not support the diagnosis of condyloma.

In SK, an alteration in the distribution of epidermal growth factor (EGF) receptors has been reported [33]. Abnormalities in the expression of growth factors and their receptors play a critical role in the development of human malignancies [34]. EGF receptors belong to the receptor tyrosine kinase superfamily. Interestingly, EGCG can block EGF receptors and at the same time, it is able to inactivate EGF [35]. Therefore, an intriguing explanation of the clinical effect of Polyphenon E we observed in this subject could be ascribed to the peculiar pharmacodynamic multiple mechanisms of this extract. In conclusion, this case report suggests that topical green tea extract could be very effective in the treatment of "seborrheic keratosis-like" lesions of the inguinal area.

\section{Statement of Ethics}

The research was conducted ethically in accordance with the World Medical Association Declaration of Helsinki. The subject has given his written informed consent to publish his case.

\section{Disclosure Statement}

L.P. and G.L. have no conflicts of interest to report. M.M. is an employee of Cantabria Labs Difa Cooper.

\section{Author Contributions}

L.P. was the physician who visited and evaluated the subject. G.L. was the pathologist who performed and evaluated the skin biopsies. M.M. contributed in the preparation of manuscript.

\section{References}

1 Tatti S, Stockfleth E, Beutner KR, Tawfik H, Elsasser U, Weyrauch P, et al. Polyphenon E: a new treatment for external anogenital warts. Br J Dermatol. 2010 Jan;162(1):176-84.

2 Stockfleth E, Beti H, Orasan R, Grigorian F, Mescheder A, Tawfik H, et al. Topical Polyphenon E in the treatment of external genital and perianal warts: a randomized controlled trial. Br J Dermatol. 2008 Jun;158(6):1329-38.

3 Waltner-Law ME, Wang XL, Law BK, Hall RK, Nawano M, Granner DK. Epigallocatechin gallate, a constituent of green tea, represses hepatic glucose production. J Biol Chem. 2002 Sep;277(38):34933-40. 
4 Valcic S, Muders A, Jacobsen NE, Liebler DC, Timmermann BN. Antioxidant chemistry of green tea catechins. Identification of products of the reaction of (-)-epigallocatechin gallate with peroxyl radicals. Chem Res Toxicol. 1999 Apr;12(4):382-6.

5 Masuda M, Suzui M, Weinstein IB. Effects of epigallocatechin-3-gallate on growth, epidermal growth factor receptor signaling pathways, gene expression, and chemosensitivity in human head and neck squamous cell carcinoma cell lines. Clin Cancer Res. 2001 Dec;7(12):4220-9.

6 Gross G, Meyer KG, Pres H, Thielert C, Tawfik H, Mescheder A. A randomized, double-blind, four-arm parallel-group, placebo-controlled Phase II/III study to investigate the clinical efficacy of two galenic formulations of Polyphenon E in the treatment of external genital warts. J Eur Acad Dermatol Venereol. 2007 Nov;21(10):1404-12.

7 Meloni G, Milani M. Efficacy and Tolerability of Topical Green Tea Extract (Polyphenon E) Application in a “Therapy-Resistant" Plantar Wart. Case Rep Dermatol. 2018 May;10(2):127-32.

8 Gandolfi M, Satolli F, Rovesti M, Zucchi A, Milani M, Lotti T, et al. Topical sinecatechins in the treatment of verrucae planae of the face. Dermatol Ther (Heidelb). 2019 May;32(3):e12891.

9 Hafner C, Vogt T. Seborrheic keratosis. J Dtsch Dermatol Ges. 2008 Aug;6(8):664-77.

$10 \mathrm{Li} \mathrm{J}$, Ackerman AB. "Seborrheic keratoses" that contain human papillomavirus are condylomata acuminata. Am J Dermatopathol. 1994 Aug;16(4):398-405.

11 Tzellos TG, Sardeli C, Lallas A, Papazisis G, Chourdakis M, Kouvelas D. Efficacy, safety and tolerability of green tea catechins in the treatment of external anogenital warts: a systematic review and meta-analysis. J Eur Acad Dermatol Venereol. 2011 Mar;25(3):345-53.

12 Milani M, Aimi F. Efficacy and Tolerability of Topical Green Tea Extract (Polyphenon E) application in "Therapy-Resistant" common and flat warts (verrucae planae): A report of two cases. Journal of Dermatology and Cosmetic Treatment. 2018;1(1):1-3.

13 Nihal M, Ahmad N, Mukhtar H, Wood GS. Anti-proliferative and proapoptotic effects of (-)-epigallocatechin3-gallate on human melanoma: possible implications for the chemoprevention of melanoma. Int J Cancer. 2005 Apr;114(4):513-21.

14 Thakur VS, Ruhul Amin AR, Paul RK, Gupta K, Hastak K, Agarwal MK, et al. p53-Dependent p21-mediated growth arrest pre-empts and protects HCT116 cells from PUMA-mediated apoptosis induced by EGCG. Cancer Lett. 2010 Oct;296(2):225-32.

15 Barbosa MS, Schlegel R. The E6 and E7 genes of HPV-18 are sufficient for inducing two-stage in vitro transformation of human keratinocytes. Oncogene. 1989 Dec;4(12):1529-32.

16 Jackson JM, Alexis A, Berman B, Berson DS, Taylor S, Weiss JS. Current understanding of seborrheic keratosis: prevalence, etiology, clinical presentation, diagnosis, and management. Journal of drugs in dermatology. J Drugs Dermatol. 2015 Oct;14(10):1119-25.

17 Taylor SC. Epidemiology of skin diseases in people of color. Cutis. 2003 Apr;71(4):271-5.

18 Tardío JC, Bancalari E, Moreno A, Martín-Fragueiro LM. Genital seborrheic keratoses are human papillomavirus-related lesions. A linear array genotyping test study. APMIS. 2012 Jun;120(6):477-83.

19 Leonardi CL, Zhu WY, Kinsey WH, Penneys NS. Seborrheic keratoses from the genital region may contain human papillomavirus DNA. Arch Dermatol. 1991 Aug;127(8):1203-6.

20 Bai H, Cviko A, Granter S, Yuan L, Betensky RA, Crum CP. Immunophenotypic and viral (human papillomavirus) correlates of vulvar seborrheic keratosis. Hum Pathol. 2003 Jun;34(6):559-64.

21 Grimes PE, Arora S, Minus HR, Kenney JA Jr. Dermatosis papulosa nigra. Cutis. 1983 Oct;32(4):385-6.

22 Hairston MA Jr, Reed RJ, Derbes VJ. Dermatosis papulosa nigra. Arch Dermatol. 1964 May;89(5):655-8.

23 Metin SA, Lee BW, Lambert WC, Parish LC. Dermatosis papulosa nigra: a clinically and histopathologically distinct entity. Clin Dermatol. 2017 Sep-Oct;35(5):491-6.

24 Wade TR, Kopf AW, Ackerman AB. Bowenoid papulosis of the genitalia. Arch Dermatol. 1979 Mar;115(3):306-8.

25 Schwartz RA, Janniger CK. Bowenoid papulosis. J Am Acad Dermatol. 1991 Feb;24(2 Pt 1):261-4.

26 Wade TR, Kopf AW, Ackerman AB. Bowenoid papulosis of the penis. Cancer. 1978 Oct;42(4):1890-903.

27 Ikenberg H, Gissmann L, Gross G, Grussendorf-Conen EI, zur Hausen H. Human papillomavirus type-16related DNA in genital Bowen's disease and in Bowenoid papulosis. Int J Cancer. 1983 Nov;32(5):563-5.

28 Gimeno E, Vilata JJ, Sanchez JL, Lloret A, Fortea JM. Bowenoid papulosis: clinical and histological study of eight cases. Genitourin Med. 1987 Apr;63(2):109-13.

29 Elgart GW. Seborrheic keratoses, solar lentigines, and lichenoid keratoses. Dermatoscopic features and correlation to histology and clinical signs. Dermatol Clin. 2001 Apr;19(2):347-57.

30 Eads TJ, Hood AF, Chuang TY, Faust HB, Farmer ER. The diagnostic yield of histologic examination of seborrheic keratoses. Arch Dermatol. 1997 Nov;133(11):1417-20.

31 Wu YH, Hsiao PF, Chen CK. Seborrheic keratosis with bowenoid transformation: the immunohistochemical features and its association with human papillomavirus infection. Am J Dermatopathol. 2015 Jun;37(6): 462-8.

32 Wu YH, Hsiao PF, Chen CK. Histopathologic and immunohistochemical distinction of condyloma and seborrheic keratosis in the genitofemoral area. Zhonghua Pifuke Yixue Zazhi. 2013;31(2):54-8. 


\section{Case Reports in Dermatology}

33 Ellis DL, Nanney LB, King LE Jr. Increased epidermal growth factor receptors in seborrheic keratoses and acrochordons of patients with the dysplastic nevus syndrome. J Am Acad Dermatol. 1990 Dec;23(6 Pt 1):1070-7.

34 Pastore S, Mascia F, Mariani V, Girolomoni G. The epidermal growth factor receptor system in skin repair and inflammation. J Invest Dermatol. 2008 Jun;128(6):1365-74.

35 Shimizu M, Deguchi A, Lim JT, Moriwaki H, Kopelovich L, Weinstein IB. (-)-Epigallocatechin gallate and polyphenon E inhibit growth and activation of the epidermal growth factor receptor and human epidermal growth factor receptor-2 signaling pathways in human colon cancer cells. Clin Cancer Res. 2005 Apr;11(7):2735-46.

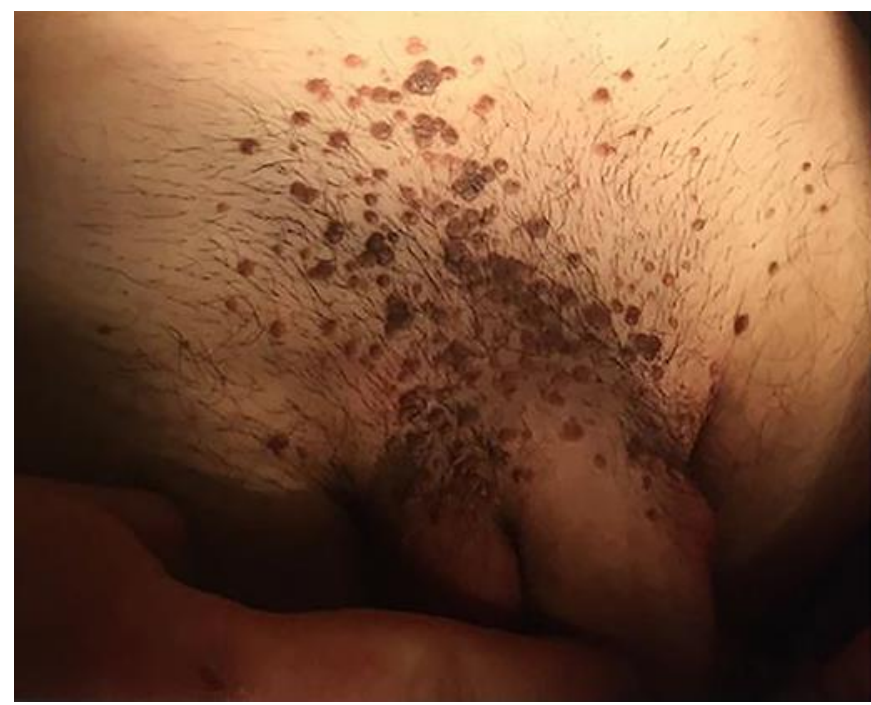

Fig. 1. Baseline visit: multiple dome-shaped lesions of the groin area.

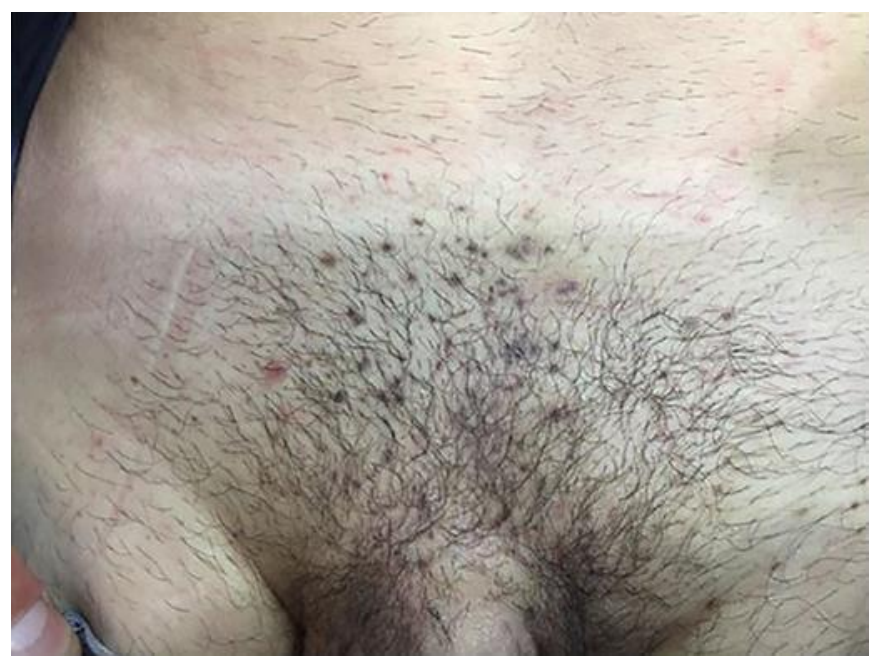

Fig. 2. After 2-month of Polyphenon E 10\% treatment. 


\section{Case Reports in Dermatology}

www.karger.com/cde

Pizzini et al.: Poliphenon E in Seborrheic Keratosis of the Genital Area
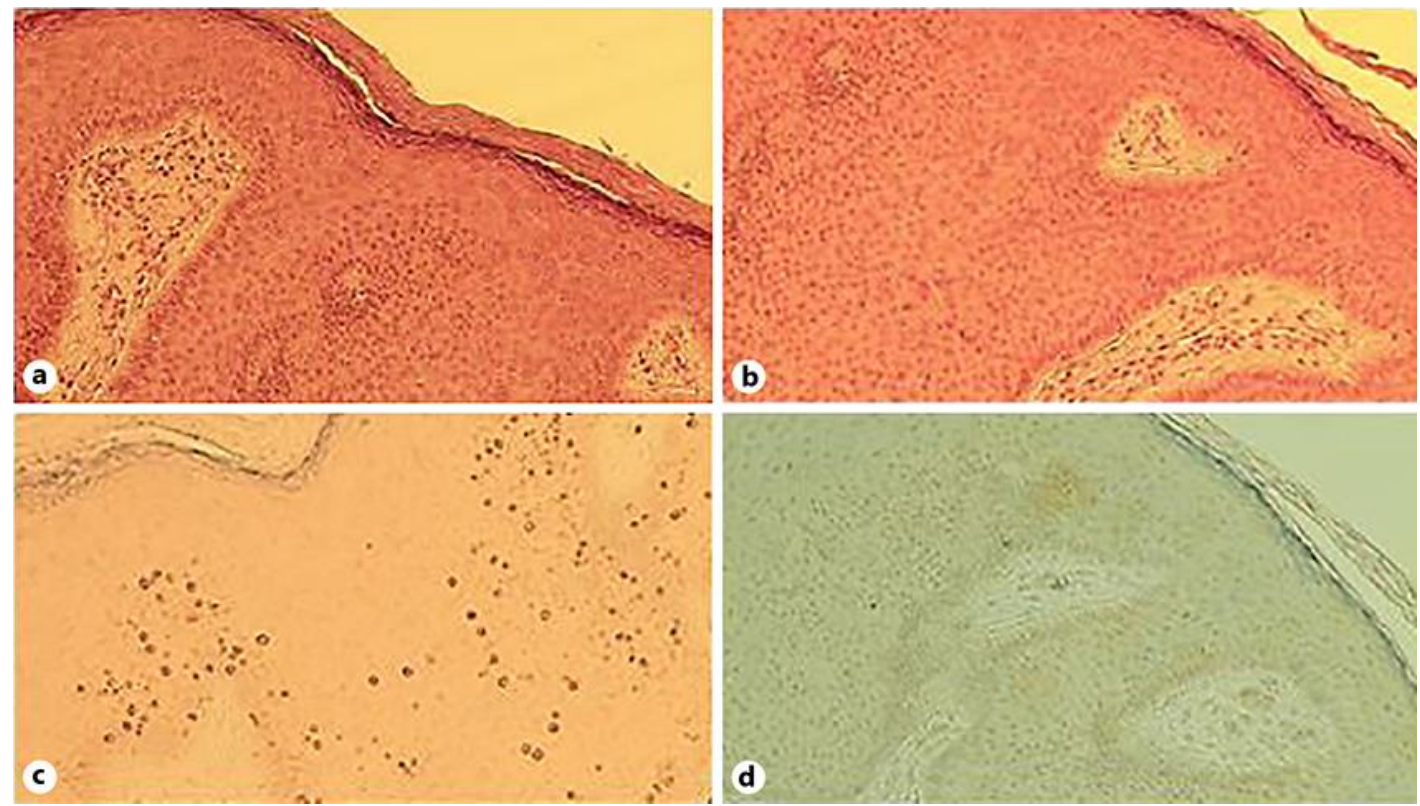

Fig. 3. Histological evaluation of the lesions. a Hematoxylin and eosin staining: mild hyperkeratosis, epidermal acanthosis, minimal dyskeratosis, absence of clear dysplasia and basal pigmentation. $\mathbf{b}$ Hematoxylin and eosin staining: mild hyperkeratosis, epidermal acanthosis, minimal dyskeratosis, absence of clear dysplasia and basal pigmentation. c ki67 expression. 100x: expression of proliferation marker only in the lowest layers of the epidermis (basal and parabasal). $\mathbf{d}$ p16 expression. 100x: complete absence of immunoreaction to $\mathrm{p} 16$ in the acanthotic lesion. 